\title{
Medical therapy following hospitalization for heart failure with reduced ejection fraction and association with discharge to long-term care: a cross-sectional analysis of the REasons for Geographic And Racial Differences in Stroke (REGARDS) population
}

Emily B. Levitan ${ }^{1,4^{*}}$, Melissa K. Van Dyke², Ligong Chen ${ }^{1}$, Raegan W. Durant ${ }^{1}$, Todd M. Brown ${ }^{1}$, J. David Rhodes ${ }^{1}$, Olusola Olubowale', Oluwole Muyiwa Adegbala', Meredith L. Kilgore', Justin Blackburn', Karen C. Albright ${ }^{1}$ and Monika M. Safford ${ }^{3}$

\begin{abstract}
Background: Less intensive treatment for heart failure with reduced ejection fraction (HFrEF) may be appropriate for patients in long-term care settings because of limited life expectancy, frailty, comorbidities, and emphasis on quality of life.

Methods: We compared treatment patterns between REasons for Geographic And Racial Differences in Stroke (REGARDS) study participants discharged to long-term care versus home following HFrEF hospitalizations. We examined medical records and Medicare pharmacy claims for $147 \mathrm{HFrEF}$ hospitalizations among 80 participants to obtain information about discharge disposition and medication prescriptions and fills.

Results: Discharge to long-term care followed 22 of $147 \mathrm{HFrEF}$ hospitalizations (15\%). Participants discharged to long-term care were more likely to be prescribed beta-blockers and less likely to be prescribed aldosterone receptor antagonists and hydralazine/isosorbide dinitrate (96\%, 14\%, and 5\%, respectively) compared to participants discharged home $(81 \%, 22 \%$, and $23 \%$, respectively). The percentages of participants discharged to long-term care and home who had claims for filled prescriptions were similar for beta-blockers (68\% versus 66\%) and angiotensin converting enzyme inhibitors or angiotensin receptor blockers (ACEI/ARBs) (45\% versus 47\%) after 1 year. Smaller percentages of participants discharged to long-term care had claims for filled prescriptions of other medications compared to participants discharged home (diuretics: long-term care-50\%, home-72\%; hydralazine/isosorbide dinitrate: long-term care-5\%, home-23\%; aldosterone receptor antagonists: long-term care-5\%, home-23\%).
\end{abstract}

Conclusions: Differences in medication prescriptions and fills among individuals with HFrEF discharged to long-term care versus home may reflect prioritization of some medical therapies over others for patients in long-term care.

Keywords: Heart failure, Therapy, Long-term care

\footnotetext{
* Correspondence: elevitan@uab.edu

${ }^{1}$ University of Alabama at Birmingham, Birmingham, AL, USA

${ }^{4}$ Department of Epidemiology, University of Alabama at Birmingham, 1720

2nd Ave S, RPHB 220, Birmingham, AL 35294-0022, USA

Full list of author information is available at the end of the article
} 


\section{Background}

Heart failure (HF) is common in populations residing in long-term care settings, with estimates of HF prevalence ranging from a fifth to a third of all patients in longterm care facilities [1-6]. In the Get With The Guidelines-HF registry, one in five hospitalized HF patients were discharged to skilled nursing facilities, and these patients had higher rates of mortality and rehospitalization than patients discharged home [7]. Guidelineconcordant pharmacologic therapy is generally recommended for patients with HF discharged to long-term care [4]. For patients with HF with reduced ejection fraction (HFrEF), diuretics-particularly loop diuretics, angiotensin converting enzyme inhibitors or angiotensin receptor blockers (ACEI/ARB), beta-blockers-particularly carvedilol, metoprolol succinate, and bisoprolol (HFrEF recommended beta-blockers), and aldosterone receptor antagonists may improve quality of life and reduce mortality and rehospitalization [8]. Hydralazine and isosorbide dinitrate in combination are recommended for black individuals already receiving maximal beta-blocker and ACEI therapy or for persons of any race unable to tolerate an ACEI or an ARB [8]. With the exception of diuretics, the effectiveness of recommended pharmacologic therapies is supported by large, high-quality randomized controlled clinical trials [8]. However, none of the trials included patients in long-term care, and these patients may be more susceptible to side effects and have limited life expectancy [4]. These characteristics suggest that less aggressive treatment for HFrEF could be appropriate for many patients discharged to long-term care. In particular, for individuals with limited life expectancy, therapies which improve quality of life and reduce hospitalization may be prioritized above therapies that prolong life at the expense of greater side effects. A recent statement from the American Heart Association and the Heart Failure Society of America emphasized individualized care planning for patients with HF in long-term care, but differences in treatment for those individuals with $\mathrm{HF}$ discharged to long-term care versus discharged to home are not well-described [4]. In this study, we examined medication treatment patterns among black and white participants of the REasons for Geographic And Racial Differences in Stroke (REGARDS) study who experienced HFrEF hospitalizations and compared treatment patterns between participants discharged to long-term care and those discharged home.

\section{Methods}

\section{Study population}

The REGARDS study population includes 30,239 white and black women and men 45 years of age and older at the time of study entry (2003-2007) from across the 48 continental United States (US) [9]. Potentially eligible individuals were identified through commercial lists. The study was designed to investigate the racial and regional differences in stroke mortality; black individuals and residents of the US Stroke Belt (North Carolina, South Carolina, Georgia, Alabama, Arkansas, Louisiana, Mississippi, and Tennessee) were oversampled. Participants completed a telephone interview followed by a home visit conducted by a trained health professional. We linked participants' information to Medicare claims using social security number, date of birth, and sex [10].

For this study, we included REGARDS participants who had one or more Medicare claims for hospitalizations with $\mathrm{HF}$ as the primary discharge diagnosis (International Classification of Diseases, 9th edition, (ICD-9) diagnosis codes 402.01, 402.11, 402.91, 404.01, $404.03,404.11,404.13,404.91,404.93,428.0,428.1$, $428.20,428.21,428.22,428.23,428.30,428.31,428.32$, $428.33,428.40,428.41,428.42,428.43$, or 428.9$)$ in 2006-2011 and Medicare inpatient and prescription drug coverage at the time of hospitalization. Multiple hospitalizations could be included for each individual. We identified 612 HF hospitalization claims, from which records were retrieved and abstracted for 400 hospitalizations among 232 unique participants. Study investigators (OO, OMA, JDR) abstracted information on comorbidities, ejection fraction, in-hospital treatment, and discharge disposition using a standardized data abstraction form. HFrEF hospitalizations were defined as those with documented ejection fraction $<40 \%$, a qualitative report of low ejection fraction, or a Medicare ICD-9 diagnosis specifying systolic dysfunction $(428.2 \mathrm{x}$ or $428.4 x$ ) during the current hospitalization or, in the absence of information about ejection fraction during the current hospitalization, a history of ejection fraction $<40 \%$ or qualitative report of low ejection fraction during a prior medical encounter. We excluded 56 hospitalizations without discharge medication lists in the retrieved medical records, 152 hospitalizations for $\mathrm{HF}$ with preserved ejection fraction and 45 hospitalizations without documentation of ejection fraction. The analytic dataset included 147 hospitalizations among 80 unique individuals with HFrEF where the participant was discharged alive and hospitalization records with discharge medication lists could be retrieved.

This research was supported by an academic collaboration between University of Alabama at Birmingham and Amgen, Inc. The funders provided comments on the design and interpretation of this work. The academic authors conducted all analyses and maintained the rights to publish this manuscript.

\section{Discharge disposition}

Discharge disposition was determined based on review of medical records. Discharge disposition was categorized as 
discharged to home, long-term care, or hospice; no participants were discharged to hospice. Long-term care included skilled nursing facilities/nursing homes and rehabilitation facilities.

\section{Covariates}

Information on age, sex, and race was collected during the REGARDS baseline interview [9]. History of asthma, chronic obstructive pulmonary disease (COPD), atrial fibrillation or flutter, peripheral vascular disease, stroke, hypertension, hypotension, diabetes, chronic kidney disease, dialysis, implanted cardiac devices, myocardial infarction, coronary heart disease, coronary heart disease events in the prior year, prior heart failure diagnosis, blood pressure at discharge, and ejection fraction were determined by medical record review. Conditions were considered to be present if there was documentation of the diagnosis in medical records (e.g., notation of hypotension). Additionally, medical record reviewers recorded whether suspected COPD exacerbation contributed to the current hospitalization and whether participants experienced hypotension during the current hospitalization. Hospitalization in the 30 days and 1 year prior to current admission, presence of outpatient clinic visits in the week after discharge, and mortality in the year following discharge were assessed using Medicare claims and enrollment information. Nursing home residence was defined as Medicare claims for care delivered in a nursing facility in the prior year; these claims are distinct from claims for the Medicare skilled nursing facility benefits that are available to beneficiaries following a hospitalization [11].

\section{Medication prescriptions and fills}

Information on prescribed medications including dose was abstracted from admission and discharge medication lists. We conducted follow-up for medication prescription fills through Medicare Part D prescription drug claims, which include information on dose, for up to one year following HFrEF hospitalization. Medicare covers up to 100 days of skilled nursing care, including prescription medications, following a hospitalization [12]. During the study period, Part D claims were submitted inconsistently during post-hospitalization periods of Medicare-covered skilled nursing care [13]. Therefore, we did not examine short-term differences in medication filling patterns.

The medications of interest included all beta-blockers, specific beta-blockers recommended for HFrEF (carvedilol, bisoprolol, or metoprolol succinate), ACEI/ARBs, diuretics, loop diuretics, and aldosterone receptor antagonists because these medications are recommended for most patients with HFrEF [8]. Because more than $40 \%$ of REGARDS participants are black [9], we additionally examined use of hydralazine in combination with isosorbide dinitrate.

\section{Statistical analysis}

We calculated means and standard deviations or numbers and percentages of demographic characteristics, comorbidities, and hospitalization characteristics overall and stratified by whether the participant was discharged to long-term care. For each medication category, we calculated the proportion with the medication on the admission and discharge medication lists and the proportion with Medicare claims for the medications within 1 year. Additionally, we calculated the percentage of the guideline-recommended target dose of specific beta-blockers recommended in HFrEF (carvedilol, bisoprolol, or metoprolol succinate) and ACEI/ARBs prescribed at discharge and filled within 1 year. These values were calculated as the dose prescribed or filled of each specific agent divided by the target dose for that agent recommended in the 2013 American College of Cardiology/American Heart Association guideline for the management of HF [8].

For each of the medications, we used generalized estimating equation Poisson models with robust variance estimators to calculate risk ratios for presence of the medications on the admission and discharge medication lists and 1-year prescription fills associated with discharge to long-term care. The generalized estimating equation approach accounted for correlations between multiple hospitalizations for a single individual. Models were adjusted for age, race, and sex.

To account for missing data in some covariates (range 0-28\% missingness), we used fully conditional specification methods to impute 20 complete datasets [14]. Analyses were conducted in each imputed dataset and point estimates and standard errors were combined across datasets accounting for the uncertainty in the imputed data [15]. All analyses were conducted using SAS version 9.3 (Cary, NC).

\section{Results}

REGARDS participants were discharged to long-term care following 22 of 147 HFrEF hospitalizations (15\%). Black participants were less likely to be discharged to long-term care than white participants (9\% versus $23 \%$ ). Participants discharged to long-term care were older, more likely to be residents of nursing homes prior to the HFrEF admission, and more likely to have been hospitalized in the 30 days and 1 year prior to the HFrEF admission (Table 1).

Pre-admission use of medications, obtained from the admission medication lists, varied from $76 \%$ using betablockers to $14 \%$ using aldosterone antagonists and hydralazine in combination with isosorbide dinitrate 
Table 1 Characteristics of HFrEF hospitalizations among participants in the REasons for Geographic and Racial Differences in Stroke (REGARDS) study by discharge status

\begin{tabular}{|c|c|c|c|}
\hline & $\begin{array}{l}\text { Overall } \\
(n=147)\end{array}$ & $\begin{array}{l}\text { Discharged to } \\
\text { long-term care } \\
(n=22)\end{array}$ & $\begin{array}{l}\text { Not discharged to } \\
\text { long-term care } \\
(n=125)\end{array}$ \\
\hline \multicolumn{4}{|l|}{ Demographics } \\
\hline \multicolumn{4}{|l|}{ Age } \\
\hline$<65$ years & $26(18 \%)$ & $1(5 \%)$ & $25(20 \%)$ \\
\hline $65-69$ years & $28(19 \%)$ & $2(9 \%)$ & $26(21 \%)$ \\
\hline 70-74 years & $30(20 \%)$ & 0 & $30(24 \%)$ \\
\hline $75-79$ years & $22(15 \%)$ & $4(18 \%)$ & $18(14 \%)$ \\
\hline $80-84$ years & $21(14 \%)$ & $9(41 \%)$ & $12(10 \%)$ \\
\hline$\geq 85$ & $20(14 \%)$ & $6(27 \%)$ & $14(11 \%)$ \\
\hline \multicolumn{4}{|l|}{ Sex } \\
\hline Female & $61(41 \%)$ & $9(41 \%)$ & $52(42 \%)$ \\
\hline Male & $86(59 \%)$ & $13(59 \%)$ & $73(58 \%)$ \\
\hline \multicolumn{4}{|l|}{ Race } \\
\hline White & $61(41 \%)$ & $14(64 \%)$ & $47(38 \%)$ \\
\hline Black & $86(59 \%)$ & $8(36 \%)$ & $78(62 \%)$ \\
\hline Nursing home resident & $14(10 \%)$ & $7(32 \%)$ & $7(6 \%)$ \\
\hline \multicolumn{4}{|l|}{ Comorbidities } \\
\hline Asthma & $20(14 \%)$ & $3(14 \%)$ & $17(14 \%)$ \\
\hline Chronic obstructive pulmonary disease & $36(24 \%)$ & $6(27 \%)$ & $30(24 \%)$ \\
\hline Atrial fibrillation/ atrial flutter & $63(43 \%)$ & $12(55 \%)$ & $51(41 \%)$ \\
\hline Peripheral vascular disease & $34(23 \%)$ & $4(18 \%)$ & $30(24 \%)$ \\
\hline Stroke & $29(20 \%)$ & $4(18 \%)$ & $25(20 \%)$ \\
\hline Hypertension & $140(95 \%)$ & $20(91 \%)$ & $120(96 \%)$ \\
\hline Hypotension history & $12(8 \%)$ & $3(14 \%)$ & $9(7 \%)$ \\
\hline Diabetes & $96(65 \%)$ & $10(45 \%)$ & $86(69 \%)$ \\
\hline Chronic kidney disease & $69(47 \%)$ & $11(50 \%)$ & $58(46 \%)$ \\
\hline Dialysis & $22(15 \%)$ & $4(18 \%)$ & $18(14 \%)$ \\
\hline Implanted cardiac device & $54(37 \%)$ & $7(32 \%)$ & $47(38 \%)$ \\
\hline Myocardial infarction & $53(36 \%)$ & $8(36 \%)$ & $45(36 \%)$ \\
\hline Coronary heart disease history & $113(77 \%)$ & $18(82 \%)$ & $95(76 \%)$ \\
\hline Coronary heart disease event within past 12 months & $15(10 \%)$ & $2(9 \%)$ & $13(10 \%)$ \\
\hline Prior heart failure diagnosis & $137(93 \%)$ & $21(95 \%)$ & $116(93 \%)$ \\
\hline Hospitalization in 30 days before admission & $34(23 \%)$ & $9(41 \%)$ & $25(20 \%)$ \\
\hline Hospitalization in 1 year before admission & $112(76 \%)$ & $18(82 \%)$ & $94(75 \%)$ \\
\hline \multicolumn{4}{|l|}{ Hospitalization information } \\
\hline Ejection fraction, mean \pm standard deviation (\%) & $33 \pm 29$ & $31 \pm 32$ & $33 \pm 29$ \\
\hline Current hypotension & $28(19 \%)$ & $4(18 \%)$ & $24(19 \%)$ \\
\hline Systolic blood pressure at discharge mean \pm standard deviation $(\mathrm{mmHg})$ & $124(24)$ & $121(28)$ & $125(24)$ \\
\hline Diastolic blood pressure at discharge mean \pm standard deviation $(\mathrm{mmHg})$ & $71(15)$ & $69(17)$ & $71(14)$ \\
\hline Chronic obstructive pulmonary disease exacerbation contributed to admission & $11(7 \%)$ & $3(14 \%)$ & $8(6 \%)$ \\
\hline Outpatient clinic visit in the week after discharge & $60(41 \%)$ & $14(64 \%)$ & $46(37 \%)$ \\
\hline Mortality within 1 year of discharge & $49(33 \%)$ & $9(41 \%)$ & $40(32 \%)$ \\
\hline
\end{tabular}


(Fig. 1). When stratified by race, $17 \%$ of black participants and $7 \%$ of white participants used hydralazine in combination with isosorbide dinitrate. All of the medications were more common on discharge than admission medication lists with percentages ranging from $87 \%$ recommended diuretics to $20 \%$ hydralazine in combination with isosorbide dinitrate $(28 \%$ of black participants and $10 \%$ of white participants) at discharge. For beta-blockers, ACEI/ARBs, and diuretics, the percentages of participants with evidence of prescriptions filled after follow-up for up to 1 year was substantially lower than the percentages with the medications included on the discharge medication lists.

Participants discharged to long-term care were more likely to have used beta-blockers and diuretics and less likely to have used hydralazine in combination with isosorbide dinitrate and aldosterone receptor antagonists prior to the HFrEF hospitalization compared to those discharged home (Table 2). At discharge, participants discharged to long-term care were more likely to have been prescribed beta-blockers and less likely to have been prescribed hydralazine in combination with isosorbide dinitrate and aldosterone receptor antagonists. For beta-blockers and ACEI/ARBs, the percentages of participants discharged to long-term care and home who had claims for filled prescriptions were similar after 1 year. Smaller percentages of participants discharged to longterm care had claims for filled prescriptions of other

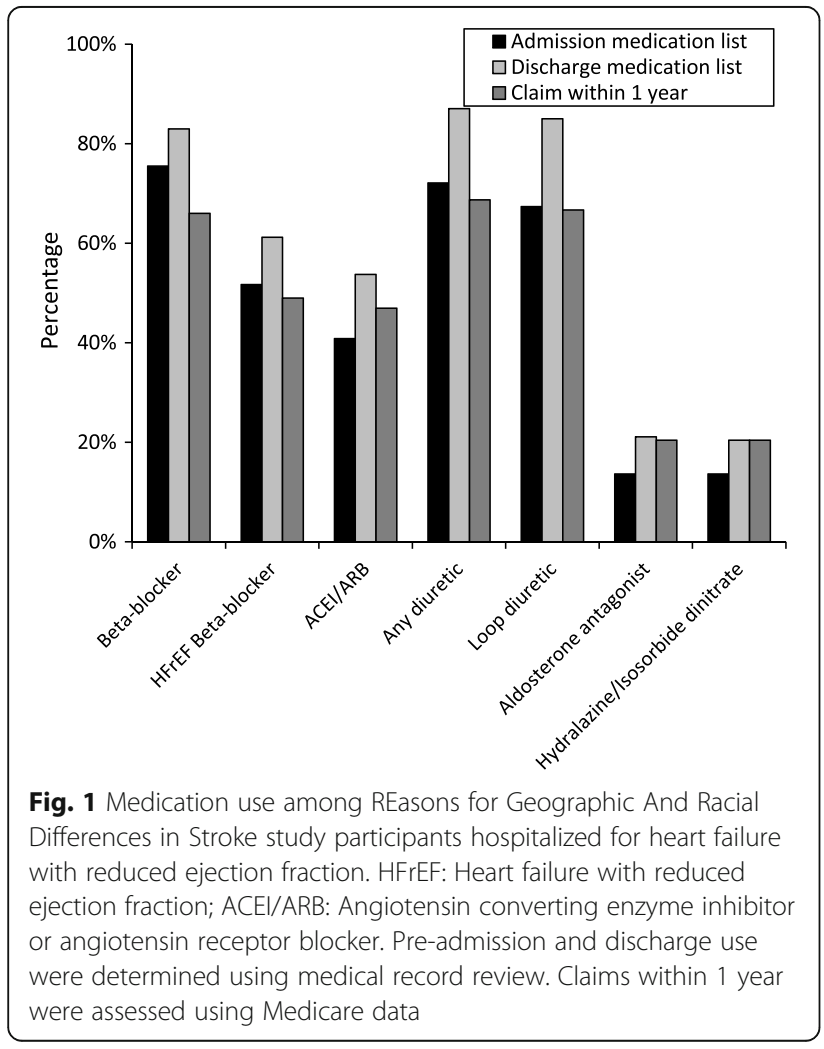

Table 2 Medication use among REGARDS participants hospitalized for HFrEF

\begin{tabular}{|c|c|c|c|}
\hline & $\begin{array}{l}\text { Admission } \\
\text { medication list }^{\mathrm{a}}\end{array}$ & $\begin{array}{l}\text { Discharge } \\
\text { medication list }^{\mathrm{a}}\end{array}$ & $\begin{array}{l}\text { Claims within } \\
1 \text { year }^{b}\end{array}$ \\
\hline \multicolumn{4}{|l|}{ Beta-blocker } \\
\hline Discharged home & $74 \%$ & $81 \%$ & $66 \%$ \\
\hline Discharged to long-term care & $82 \%$ & $95 \%$ & $68 \%$ \\
\hline \multicolumn{4}{|l|}{ HFrEF beta-blocker ${ }^{c}$} \\
\hline Discharged home & $52 \%$ & $60 \%$ & $49 \%$ \\
\hline Discharged to long-term care & $50 \%$ & $68 \%$ & $50 \%$ \\
\hline \multicolumn{4}{|l|}{ ACEI/ARB } \\
\hline Discharged home & $41 \%$ & $54 \%$ & $47 \%$ \\
\hline Discharged to long-term care & $41 \%$ & $55 \%$ & $45 \%$ \\
\hline \multicolumn{4}{|l|}{ Diuretic } \\
\hline Discharged home & $71 \%$ & $87 \%$ & $72 \%$ \\
\hline Discharged to long-term care & $77 \%$ & $86 \%$ & $50 \%$ \\
\hline \multicolumn{4}{|l|}{ Loop diuretic } \\
\hline Discharged home & $66 \%$ & $85 \%$ & $70 \%$ \\
\hline Discharged to long-term care & $77 \%$ & $86 \%$ & $50 \%$ \\
\hline \multicolumn{4}{|c|}{ Hydralazine in combination with isosorbide dinitrate } \\
\hline Discharged home & $14 \%$ & $23 \%$ & $23 \%$ \\
\hline Discharged to long-term care & $9 \%$ & $5 \%$ & $5 \%$ \\
\hline \multicolumn{4}{|l|}{ Aldosterone receptor antagonist } \\
\hline Discharged home & $14 \%$ & $22 \%$ & $23 \%$ \\
\hline Discharged to long-term care & $9 \%$ & $14 \%$ & $5 \%$ \\
\hline
\end{tabular}

HFrEF Heart failure with reduced ejection fraction, ACEI/ARB Angiotensin converting enzyme inhibitor or angiotensin receptor blocker ${ }^{a}$ Determined from review of medical records

${ }^{b}$ Determined using Medicare pharmacy claims data

${ }^{c}$ Carvedilol, metoprolol succinate, or bisoprolol

medications after 1 year compared to participants discharged home. After adjusting for age, race, and sex, participants discharged to long-term care were more likely to have beta-blockers and less likely to have aldosterone receptor antagonists and hydralazine in combination with isosorbide dinitrate on their discharge medication lists than those discharged home, although associations were not statistically significant (Table 3). For beta-blockers and ACEI/ARBs, the groups had similar proportions of fills at 1 year. Claims for diuretics, aldosterone receptor antagonists, and hydralazine in combination with isosorbide dinitrate fills remained lower among participants discharged to long-term care at 1 year. Among those prescribed and filling the medications, the average doses of HFrEF-recommended betablockers and ACEI/ARBs were lower among participants discharged to long-term care than those discharged home (Table 4). The average percentage of the guideline-recommended target doses of beta-blockers and ACEI/ARBs filled at 1 year was lower than the average percentage of the target dose indicated on the discharge prescription lists. 
Table 3 Age, race, and sex adjusted risk ratios for the associations between discharge to long-term care and medication use among REGARDS participants hospitalized for HFrEF

\begin{tabular}{|c|c|c|c|}
\hline & $\begin{array}{l}\text { Admission } \\
\text { medication list }\end{array}$ & $\begin{array}{l}\text { Discharge } \\
\text { medication list }\end{array}$ & $\begin{array}{l}\text { Claims within } \\
1 \text { year }^{\text {b }}\end{array}$ \\
\hline Beta-blocker & $1.1(0.9,1.4)$ & $1.2(1.0,1.4)$ & $1.0(0.7,1.4)$ \\
\hline HFrEF beta-blocker ${ }^{c}$ & $1.0(0.6,1.7)$ & $1.3(0.9,1.9)$ & $1.0(0.6,1.8)$ \\
\hline ACEI/ARB & $1.0(0.6,1.6)$ & $1.0(0.6,1.6)$ & $1.0(0.6,1.7)$ \\
\hline Any diuretic & $1.1(0.8,1.4)$ & $1.0(0.8,1.2)$ & $0.7(0.4,1.1)$ \\
\hline Loop diuretic & $1.2(0.9,1.6)$ & $1.0(0.8,1.2)$ & $0.7(0.4,1.1)$ \\
\hline $\begin{array}{l}\text { Aldosterone receptor } \\
\text { antagonist }\end{array}$ & $0.6(0.1,2.3)$ & $0.7(0.2,2.2)$ & $0.2(0.0,1.4)$ \\
\hline $\begin{array}{l}\text { Hydralazine in combination } \\
\text { with isosorbide dinitrate }\end{array}$ & $0.9(0.2,3.7)$ & $0.2(0.0,1.3)$ & $0.2(0.0,1.8)$ \\
\hline
\end{tabular}

HFrEF Heart failure with reduced ejection fraction, ACEI/ARB Angiotensin converting enzyme inhibitor or angiotensin receptor blocker

a Determined from review of medical records

${ }^{b}$ Determined using Medicare claims data

cCarvedilol, metoprolol succinate, or bisoprolol

\section{Discussion}

In this population of black and white US adults hospitalized for HFrEF, we found that the majority were prescribed beta-blockers and diuretics at discharge, regardless of discharge disposition. Many individuals received beta-blockers other than the 3 that have been shown to have benefit for patients with HFrEF in clinical trials. ACEI/ARBs were prescribed for approximately half and aldosterone receptor antagonists and hydralazine in combination with isosorbide dinitrate were prescribed for approximately one fifth of participants, also with little difference between participants discharged to long-term care and those discharged home. The

Table 4 Average percentage of target dose of medications ${ }^{a}$ among REGARDS participants hospitalized for HFrEF

\begin{tabular}{|c|c|c|}
\hline & $\begin{array}{l}\text { Discharge } \\
\text { medication list }\end{array}$ & $\begin{array}{l}\text { Claims within } \\
1 \text { year }^{c}\end{array}$ \\
\hline \multicolumn{3}{|l|}{ HFrEF beta-blocker $^{d}$} \\
\hline Discharged home & $35 \%$ & $23 \%$ \\
\hline Discharged to long-term care & $22 \%$ & $20 \%$ \\
\hline \multicolumn{3}{|l|}{ ACEI/ARB } \\
\hline Discharged home & $153 \%$ & $86 \%$ \\
\hline Discharged to long-term care & $63 \%$ & $50 \%$ \\
\hline
\end{tabular}

HFrEF Heart failure with reduced ejection fraction, ACEI/ARB Angiotensin converting enzyme inhibitor or angiotensin receptor blocker

${ }^{a}$ Calculated as the dose prescribed or filled of the specific agent divided by the target dose for that agent recommended in the 2013 American College of Cardiology/American Heart Association guideline for the management of heart failure

${ }^{b}$ Determined from review of medical records among those with the medication on their discharge medication

'Determined using Medicare pharmacy claims data among those with claims for the medication

${ }^{\mathrm{d} C}$ Carvedilol, metoprolol succinate, or bisoprolol proportion of participants with Medicare claims for beta-blockers and ACEI/ARBs was similar across discharge status, but the proportion with claims for other medications was smaller among participants discharged to long-term care. The proportion of REGARDS participants with HFrEF discharged to long-term care was lower than the proportion discharged to long-term care in Get With The Guidelines-HF registry [7]. More than half of the HFrEF hospitalizations occurred among black REGARDS participants who were less likely than white participants to be discharged to long-term care, consistent with other US studies [16].

Pharmacologic therapies for HFrEF can impose a substantial burden of side effects, costs, and need for medical care. In a recent analysis, $82 \%$ of patients discharged following a hospitalization for HFrEF were eligible to initiate at least 1 new medication and 32\% were eligible to initiate 3 or more medications [17]. Patients with HFrEF, particularly those in long-term care, often have multiple comorbidities that may also warrant pharmacologic therapy $[7,18]$. In clinical practice, patients with HFrEF are often older, frailer, and have more comorbidities than participants in the landmark clinical trials of HFrEF therapy [19, 20]. Age, frailty, and comorbidities such as chronic kidney disease and COPD may decrease patients' ability to tolerate medications, alter the goals and priorities of care compared to clinical trial populations, and the applicability or perceived applicability of guidelines [4, 21]. The same patient characteristics that can limit tolerability of medications and change priorities of care also increase the probability that patients are discharged to long-term care following a HFrEF hospitalization [4, 7]. Patients discharged to long-term care following hospitalization are a mix of patients who are expected to return to independent living following a limited period of skilled nursing care, patients who will continue to require assistance with activities of daily living, and those whose ability to live independently is uncertain [4]. We were not able to distinguish between those subgroups in this study, though one third of participants discharged to long term care had been nursing home residents in the prior year. Management of HFrEF in residents of long-term care facilities requires balancing the potential cardiac benefits of therapy with risk of side effects and treatment burden, particularly among patients nearing the end of life [4]. The close observation available in a skilled nursing facility could allow providers to up-titrate medications, especially if the patient anticipates returning to independent living. However, aggressive treatment of HFrEF may not be a priority for patients in long-term care and their providers. In this study we found little difference in the medications prescribed for participants discharged to long-term care and home following a hospitalization for 
HFrEF, though doses of HFrEF-recommended betablockers and ACEI/ARBs were somewhat lower among those discharge to long-term care and Medicare claims for fills of diuretics, aldosterone receptor antagonists, and hydralazine in combination with isosorbide dinitrate were less common among participants discharged to long-term care.

Differences between the REGARDS population with hospitalizations occurring between 2006 and 2011 and previously studied populations likely reflect secular trends of increasing acceptance and use of these medications among patients with HFrEF both for individuals discharged to long-term care and home [17, 22-30]. In a previous study from the Get With The Guideline-HF registry including hospitalizations that occurred in 2005-2006, the percentages of eligible patients prescribed ACEI/ARBs (30.5\%) and beta-blockers (33.2\%) were lower than in the current study, and patients discharged to skilled nursing facilities were less likely to have been prescribed these medications [7]. Alabama patients hospitalized for HF in 1994 who were eligible for ACEIs were less likely to receive them if they were nursing home residents [31]. In an evaluation of patients with HF with both preserved and reduced ejection fraction in long-term care between 1992 and 1996, percentages using diuretics, ACEI, and beta-blockers were $45 \%$, $26 \%$, and $4 \%$, respectively [32]. In this study we focused on treatment for HFrEF because the recommended therapies for HFpEF are primarily directed at managing comorbidities and fluid overload [8].

Strengths of this study include the population of black and white adults who were recruited from across the continental US and were hospitalized in a wide range of unselected facilities, information on HFrEF hospitalizations and comorbidities obtained from chart reviews, and the availability of both discharge medication lists, reflecting planned treatments, and pharmacy fills, reflecting the treatments purchased by or on behalf of the participants. However, these results must be interpreted in light of several weaknesses. The study population was small which limited us to primarily descriptive analyses. The small study size precluded extensive multivariable adjustment, increasing the risk of uncontrolled and residual confounding. Additionally, we relied on Medicare claims to identify medication fills following hospitalization. We could not observe pharmacy fills that were not submitted for Medicare payment, particularly during periods when participants were receiving skilled nursing care reimbursed by Medicare immediately following hospitalization. Information on functional status and other factors that could influence discharge disposition was not available. Similarly, we did not have detailed information on some characteristics that could affect pharmacologic therapy. For example, we had information about diagnoses of CKD but not glomerular filtration rate or albuminuria.

\section{Conclusions}

In summary, prescriptions for beta-blockers and diuretics were common, but prescriptions for other recommended medications, including ACEI/ARBs, aldosterone receptor blockers, and hydralazine in combination with isosorbide dinitrate were much less frequent among REGARDS participants hospitalized for HFrEF regardless of discharge disposition. The proportion of participants with Medicare claims for medication fills was substantially lower than the proportion with prescriptions. Fills for beta-blockers and ACEI/ARBs, two medications targeted in performance measures [33], were largely similar in participants with HFrEF discharged to long-term care and those discharged home. Other HFrEF medications were less frequently filled among those discharged to long-term care. The observed differences in medication fills by discharge status could reflect prioritization of therapies for HFrEF patients in long-term care.

\section{Abbreviations}

ACEl: Angiotensin converting enzyme inhibitors; ARB: Angiotensin receptor blockers; HF: Heart failure; HFrEF: Heart failure with reduced ejection fraction; ICD-9: International Classification of Diseases, 9th edition; REGARDS: REasons for Geographic And Racial Differences in Stroke; US: United States

\section{Acknowledgements}

The authors thank the other investigators, the staff, and the participants of the REGARDS study for their valuable contributions. A full list of participating REGARDS investigators and institutions can be found at http://www.regardsstudy.org.

\section{Funding}

The REGARDS study is supported by a cooperative agreement U01 NS041588 from the National Institute of Neurological Disorders and Stroke, National Institutes of Health, Department of Health and Human Service. Additional support for this project was provided by an academic collaboration between University of Alabama at Birmingham and Amgen, Inc., and grants from the National Heart, Lung, and Blood Institute (K24 HL111154 and R01 HL080477). The content is solely the responsibility of the authors and does not necessarily represent the official views of the National Institute of Neurological Disorders and Stroke or the National Institutes of Health. Representatives of the funding agency have been involved in the review of the manuscript but not directly involved in the collection, management, analysis or interpretation of the data.

\section{Availability of data and materials}

The data that support this study are available from the REGARDS study (www.regardsstudy.org), but restrictions apply to the availability of these data. The data are not publicly available because they contain information that could compromise research participant privacy and consent.

\section{Authors' contributions}

EBL conceived of the study, lead the design, coordination, and statistical analysis, and drafted the manuscript. MKV conceived of the study, assisted with the design and interpretation, and revised the manuscript for important intellectual content. LC conducted the statistical analysis and revised the manuscript for important intellectual content. RWD assisted with designing the data collection forms and interpretation of results and revised the manuscript for important intellectual content. TMB assisted with designing the data collection forms and interpretation of results and revised the manuscript for important intellectual content. JDR assisted with designing the data collection forms, lead the data collection, assisted with interpretation of results and revised the manuscript for important intellectual content. $\mathrm{O}$ 
assisted with designing the data collection forms, conducted chart reviews, assisted with interpretation of results and revised the manuscript for important intellectual content. OMA assisted with designing the data collection forms, conducted chart reviews, assisted with interpretation of results and revised the manuscript for important intellectual content. MLK assisted with design and interpretation of the study and revised the manuscript for important intellectual content. JB assisted with design and interpretation of the study and revised the manuscript for important intellectual content. KCA assisted with design and interpretation of the study and revised the manuscript for important intellectual content. MMS was responsible for overall study guidance, initial collection of parent study data, assisted with design and interpretation of the study, and revised the manuscript for important intellectual content. All authors read and approved the final manuscript.

\section{Ethics approval and consent to participate}

This research was conducted in accordance with the Declaration of Helsinki. The REGARDS study was approved by the Institutional Review Boards of the University of Alabama at Birmingham, the University of Vermont, Wake Forest University, and the University of Cincinnati. Participants provided written informed consent and completed medical record release forms authorizing study investigators to retrieve medical records for research purposes. The Institutional Review Board of the University of Alabama at Birmingham approved the current research.

\section{Consent for publication}

Not applicable.

\section{Competing interests}

This research was supported by an academic collaboration between University of Alabama at Birmingham and Amgen, Inc. EBL reports serving on advisory boards for Amgen Inc. and consulting for Novartis. MKV was an employee of Amgen, Inc., at the time the work was conducted.

\section{Publisher's Note}

Springer Nature remains neutral with regard to jurisdictional claims in published maps and institutional affiliations.

\section{Author details}

${ }^{1}$ University of Alabama at Birmingham, Birmingham, AL, USA. ${ }^{2}$ Amgen Inc, Thousand Oaks, CA, USA. ${ }^{3}$ Weill Cornell Medicine, New York, NY, USA. ${ }^{4}$ Department of Epidemiology, University of Alabama at Birmingham, 1720 2nd Ave S, RPHB 220, Birmingham, AL 35294-0022, USA.

\section{Received: 2 March 2017 Accepted: 11 September 2017} Published online: 16 September 2017

\section{References}

1. Barents M, van der Horst IC, Voors AA, Hillege JL, Muskiet FA, de Jongste MJ. Prevalence and misdiagnosis of chronic heart failure in nursing home residents: the role of B-type natriuretic peptides. Neth Heart J. 2008;16(4):123-8.

2. Daamen MAMJ, Hamers JPH, Gorgels APM, Brunner-La Rocca H-P, Tan FES, Dieijen-Visser MP, Schols JMGA. Heart failure in nursing home residents; a cross-sectional study to determine the prevalence and clinical characteristics. BMC Geriatr. 2015;15(1):1-9.

3. Ahmed AA, Hays Cl, Liu B, Aban IB, Sims RV, Aronow WS, Ritchie CS, Ahmed A. Predictors of in-hospital mortality among hospitalized nursing home residents: an analysis of the National Hospital Discharge Surveys 2005-2006. J Am Med Dir Assoc. 2010;11(1):52-8.

4. Jurgens CY, Goodlin S, Dolansky M, Ahmed A, Fonarow GC, Boxer R, Arena R, Blank L, Buck HG, Cranmer K, et al. Heart failure management in skilled nursing facilities: a scientific statement from the American Heart Association and the Heart Failure Society of America. Circ Heart Fail. 2015;8(3):655-87.

5. Hancock HC, Close H, Mason JM, Murphy JJ, Fuat A, Singh R, Wood E, de Belder M, Brennan G, Hussain N, et al. High prevalence of undetected heart failure in long-term care residents: findings from the heart failure in care homes (HFinCH) study. Eur J Heart Fail. 2013;15(2):158-65.

6. Moore KL, Boscardin WJ, Steinman MA, Schwartz JB. Age and sex variation in prevalence of chronic medical conditions in older residents of U.S. nursing homes. J Am Geriatr Soc. 2012;60(4):756-64.

7. Allen LA, Hernandez AF, Peterson ED, Curtis LH, Dai D, Masoudi FA, Bhatt DL, Heidenreich PA, Fonarow GC. Discharge to a skilled nursing facility and subsequent clinical outcomes among older patients hospitalized for heart failure. Circ Heart Fail. 2011;4(3):293-300.

8. Yancy CW, Jessup M, Bozkurt B, Butler J, Casey DE Jr, Drazner MH, Fonarow GC, Geraci SA, Horwich T, Januzzi JL, et al. 2013 ACCF/AHA guideline for the management of heart failure: a report of the American College of Cardiology Foundation/American Heart Association task force on practice guidelines. Circulation. 2013;128(16):e240-327.

9. Howard VJ, Cushman M, Pulley L, Gomez CR, Go RC, Prineas RJ, Graham A, Moy CS, Howard G. The REasons for Geographic And Racial Differences in Stroke study: objectives and design. Neuroepidemiology. 2005;25(3):135-43.

10. Xie F, Colantonio LD, Curtis JR, Safford MM, Levitan EB, Howard G, Muntner $P$. Linkage of a population-based cohort with primary data collection to Medicare claims: the REasons for Geographic And Racial Differences in Stroke (REGARDS) study. Am J Epidemiol. 2016;184(7):532-544.

11. Yun H, Kilgore ML, Curtis JR, Delzell E, Gary LC, Saag KG, Morrisey MA, Becker D, Matthews R, Smith W, et al. Identifying types of nursing facility stays using Medicare claims data: an algorithm and validation. Health Serv Outcome Res Methodol. 2010;10(1-2):100-10.

12. Medicare Coverage of Skilled Nursing Facility Care [https://www.medicare. gov/Pubs/pdf/10153.pdf].

13. Levinson DR. Medicare part D payments for Benificaries in part a skilled nursing facility stays in. Department of Health and Human Services; 2006. [https://oig.hhs.gov/oei/reports/oei-02-07-00230.pdf].

14. Lee KJ, Carlin JB. Multiple imputation for missing data: fully conditional specification versus multivariate normal imputation. Am J Epidemiol. 2010;171(5):624-32

15. Schafer JL. Analysis of incomplete multivariate data. Boca Raton: CRC Press; 1997.

16. Thomeer MB, Mudrazija S, Angel JL. How do race and Hispanic ethnicity affect nursing home admission? Evidence from the Health and Retirement Study. J Gerontol B Psychol Sci Soc Sci. 2015;70(4):628-38.

17. Allen LA, Fonarow GC, Liang L, Schulte PJ, Masoudi FA, Rumsfeld JS, Ho PM Eapen ZJ, Hernandez AF, Heidenreich PA, et al. Medication initiation burden required to comply with heart failure guideline recommendations and hospital quality measures. Circulation. 2015;132(14):1347-53.

18. Caughey GE, Roughead EE, Shakib S, Vitry Al, Gilbert AL. Co-morbidity and potential treatment conflicts in elderly heart failure patients: a retrospective, cross-sectional study of administrative claims data. Drugs Aging. 2011;28(7):575-81.

19. Heiat A, Gross CP, Krumholz HM. Representation of the elderly, women, and minorities in heart failure clinical trials. Arch Intern Med. 2002;162(15):1682-8.

20. Masoudi FA, Havranek EP, Wolfe P, Gross CP, Rathore SS, Steiner JF, Ordin DL Krumholz HM. Most hospitalized older persons do not meet the enrollment criteria for clinical trials in heart failure. Am Heart J. 2003;146(2):250-7.

21. Steinman MA, Sudore RL, Peterson CA, Harlow JB, Fried TR. Influence of patient age and comorbid burden on clinician attitudes toward heart failure guidelines. Am J Geriatr Pharmacother. 2012;10(3):211-8.

22. Lee DS, Tu JV, Juurlink DN, Alter DA, Ko DT, Austin PC, Chong A, Stukel TA, Levy D, Laupacis A. Risk-treatment mismatch in the pharmacotherapy of heart failure. JAMA. 2005;294(10):1240-7.

23. Patel $P$, White $D L$, Deswal $A$. Translation of clinical trial results into practice: temporal patterns of beta-blocker utilization for heart failure at hospital discharge and during ambulatory follow-up. Am Heart J. 2007;153(4):515-22.

24. Ushigome R, Sakata Y, Nochioka K, Miyata S, Miura M, Tadaki S, Yamauchi T, Sato $\mathrm{K}$, Onose T, Tsuji $\mathrm{K}$, et al. Temporal trends in clinical characteristics, management and prognosis of patients with symptomatic heart failure in Japan- report from the CHART studies. Circ J. 2015;79(11):2396-407.

25. Cohen Solal A, Leurs I, Assyag P, Beauvais F, Clerson P, Contre C, Thebaut JF, Genoun M, French National College of Cardiologists. Optimization of heart FailUre medical treatment after hospital discharge according to left ventricUlaR ejection fraction: the FUTURE survey. Arch Cardiovasc Dis. 2012;105(6-7):355-65.

26. Hernandez AF, Hammill BG, O'Connor CM, Schulman KA, Curtis LH, Fonarow GC. Clinical effectiveness of beta-blockers in heart failure: findings from the OPTIMIZE-HF (Organized Program to Initiate Lifesaving Treatment in Hospitalized Patients with Heart Failure) registry. J Am Coll Cardiol. 2009; 53(2):184-92.

27. Fonarow GC, Abraham WT, Albert NM, Stough WG, Gheorghiade M, Greenberg $\mathrm{BH}, \mathrm{O}$ 'Connor CM, Sun JL, Yancy CW, Young JB. Prospective evaluation of betablocker use at the time of hospital discharge as a heart failure performance measure: results from OPTIMIZE-HF. J Card Fail. 2007;13(9):722-31. 
28. Steinberg BA, Zhao X, Heidenreich PA, Peterson ED, Bhatt DL, Cannon CP, Hernandez AF, Fonarow GC, Get With the Guidelines Scientific Advisory Committee and Investigators. Trends in patients hospitalized with heart failure and preserved left ventricular ejection fraction: prevalence, therapies, and outcomes. Circulation. 2012;126(1):65-75.

29. DiMartino LD, Shea AM, Hernandez AF, Curtis LH. Use of guidelinerecommended therapies for heart failure in the Medicare population. Clin Cardiol. 2010;33(7):400-5.

30. Cleland JG, Cohen-Solal A, Aguilar JC, Dietz R, Eastaugh J, Follath F, Freemantle N, Gavazzi A, van Gilst WH, Hobbs FD, et al. Management of heart failure in primary care (the IMPROVEMENT of heart failure Programme): an international survey. Lancet. 2002;360(9346):1631-9.

31. Ahmed A, Weaver MT, Allman RM, DeLong JF, Aronow WS. Quality of care of nursing home residents hospitalized with heart failure. J Am Geriatr Soc. 2002:50(11):1831-6.

32. Gambassi G, Forman DE, Lapane KL, Mor V, Sgadari A, Lipsitz LA, Bernabei R. Management of heart failure among very old persons living in long-term care: has the voice of trials spread? The SAGE study group. Am Heart J. 2000;139(1 Pt 1):85-93.

33. Bonow RO, Ganiats TG, Beam CT, Blake K, Casey DE, Goodlin SJ, Grady KL, Hundley RF, Jessup M, et al. ACCF/AHA/AMA-PCPI 2011 performance measures for adults with heart failure: a report of the American College of Cardiology Foundation/American Heart Association task force on performance measures and the American Medical Association-physician consortium for performance Improvement. Circulation. 2012;125(19):2382-401.

\section{Submit your next manuscript to BioMed Central and we will help you at every step:}

- We accept pre-submission inquiries

- Our selector tool helps you to find the most relevant journal

- We provide round the clock customer support

- Convenient online submission

- Thorough peer review

- Inclusion in PubMed and all major indexing services

- Maximum visibility for your research

Submit your manuscript at www.biomedcentral.com/submit

) Biomed Central 